\title{
Technology Development Roadmaps - A Systematic Approach to Maturing Needed Technologies
}

INCOSE 2010

John W. Collins

Layne Pincock

The INL is a

U.S. Department of Energy

National Laboratory

operated by

Battelle Energy Alliance

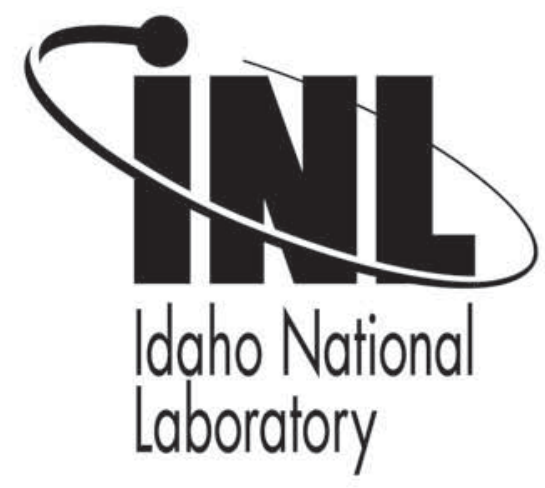

This is a preprint of a paper intended for publication in a journal or proceedings. Since changes may be made before publication, this preprint should not be cited or reproduced without permission of the author. This document was prepared as an account of work sponsored by an agency of the United States Government. Neither the United States Government nor any agency thereof, or any of their employees, makes any warranty, expressed or implied, or assumes any legal liability or responsibility for any third party's use, or the results of such use, of any information, apparatus, product or process disclosed in this report, or represents that its use by such third party would not infringe privately owned rights. The views expressed in this paper are not necessarily those of the United States Government or the sponsoring agency. 


\title{
Technology Development Roadmaps - A Systematic Approach to Maturing Needed Technologies
}

\author{
John W. Collins \\ 208-526-3372 \\ john.collins@inl.gov \\ Layne Pincock \\ 208-526-0985 \\ layne.pincock@inl.gov \\ Idaho National Laboratory \\ 2525 N. Fremont Ave. \\ P.O. Box 1625 \\ Idaho Falls, ID 83415-3780 \\ Copyright @ 2010 by Battelle Energy Alliance, LLC. Published and used by INCOSE with permission.
}

\begin{abstract}
Planning and decision making represent important challenges for all projects. This paper outlines the steps used to determine technical readiness and map the path forward to systematically advance readiness to support detailed design of the Next Generation Nuclear Plant. A Technology Readiness Assessment is used to evaluate the required systems, subsystems, and components (SSC) comprising the desired plant architecture and assess the SSCs against established Technology Readiness Levels (TRLs). A validated TRL baseline is then established for the proposed physical design. Technology Development Roadmaps are generated to define the path forward and focus project engineering and research and development tasks on advancing the technologies to increasing levels of maturity. Tasks include modeling, testing, bench-scale demonstrations, pilot-scale demonstrations, and fully integrated prototype demonstrations. The roadmaps identify precise project objectives and requirements; create a consensus vision of project needs; provide a structured, defensible, decision-based project plan; and minimize project costs and schedules.
\end{abstract}

\section{Introduction}

Industry experience repeatedly demonstrates the consequences of proceeding with projects that employ technologies that are not sufficiently mature. The U.S. General Accounting Office (GAO) noted that these consequences manifest themselves as cost overruns and schedule delays late in the project life cycle [Ref. GAO]. To avoid these undesirable consequences, the Next Generation Nuclear Plant (NGNP) project initiated efforts to assess the technology readiness of critical systems, subsystems, and components (SSC) and identify the steps required to ensure sufficient maturity prior to inclusion in the NGNP design. This paper discusses the process used and experience gained in establishing a baseline for the current technology readiness status and a path forward that achieves increasing levels of technical maturity. The critical SSCs, their current state of readiness, and the steps needed to demonstrate increasing levels of technical maturity are documented in Technology Development Roadmaps (TDRMs). As these TDRMs are executed, project risk is reduced and the likelihood of within-budget and on-schedule completion is enhanced. 


\section{Background -Strategic, Technology, and Implementation Roadmaps}

Building on core roadmapping principles that have guided Fortune 500 companies like Intel and Motorola, the Idaho National Laboratory (INL) has developed a specialized planning, decision analysis, and roadmapping capability that provides the rigor and understanding needed for decision-makers to focus on critical uncertainties; make informed, defensible decisions; and drive a project to successful completion under the critical eye of stakeholders [Ref. Collins; Grinnell].

Roadmaps differ by project, application, and intent, and no two roadmaps are ever the same. The INL uses three different types of roadmaps: Strategic, Technology, and Implementation, as depicted in Figure 1.

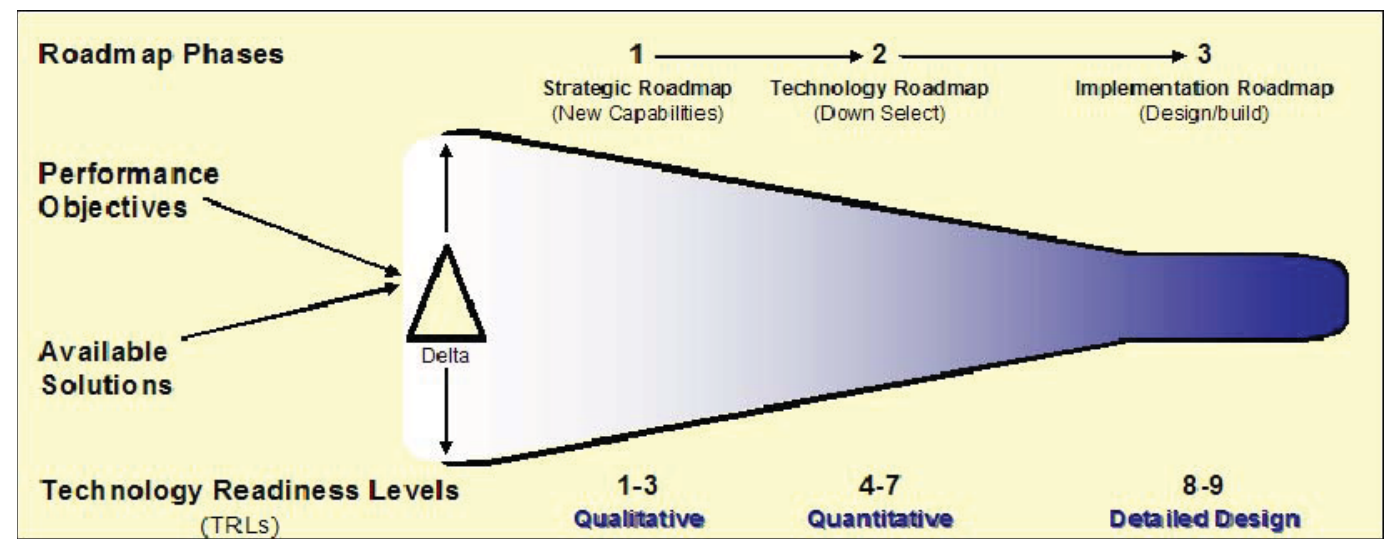

Figure 1. Different Roadmaps for Different Applications

Strategic roadmaps are typically developed at early stages of a project [Ref. U.S. DOE, 2002]. They serve to:

- Create consensus vision of project needs based on needed capabilities

- Identify clear project objectives

- Provide early identification of high-risk items and allow early focused attention to meet the mission

- Support engineering, research and development (R\&D), and management priorities.

Technology roadmaps are established as the system architecture and concept of operations are being developed and are useful to depict the path forward to down select technologies and mature components into subsystems and operable systems [Ref. American Forest; Glass; Thompson]. Technology roadmaps:

- Focus resources on critical technologies

- Identify key technology decision points and the scientific and technical information necessary to make informed decisions

- Provide early identification and management of technical risks 
- Ensure technology readiness is demonstrated through testing, modeling, piloting, and prototyping

- Enhance project cost and schedule success.

Implementation roadmaps are used to create the path forward to verify and validate processes and to drive process enhancements [Ref. U.S. DOE, 2000]. Implementation roadmaps:

- Depict the approach to systematically evaluate existing systems for performance and efficiency enhancements

- Verify and validate that the needed capability is delivered.

This paper focuses on the technology roadmaps created for the NGNP project and the methods used in the creation of these NGNP TDRMs.

\section{Technology Readiness Assessment of the NGNP}

A key step in the creation of the NGNP TDRMs was the initial Technical Readiness Assessment. The Technology Readiness Assessment process, which originated with NASA and the U.S. Department of Defense (DOD) [Ref. U.S. DOD], evaluates the deployment readiness of a technology, system, or component, in other words, its readiness to function in an integrated environment. A Technology Readiness Level (TRL) is assigned to each evaluated technology based on its relative level of development toward deployment. The NGNP uses TRLs with a tailored scale of 1 to 10, which expands the NASA and DOE scales to include one additional level that indicates readiness for commercial-scale production. Abbreviated TRL definitions are shown in Figure Figure 2.

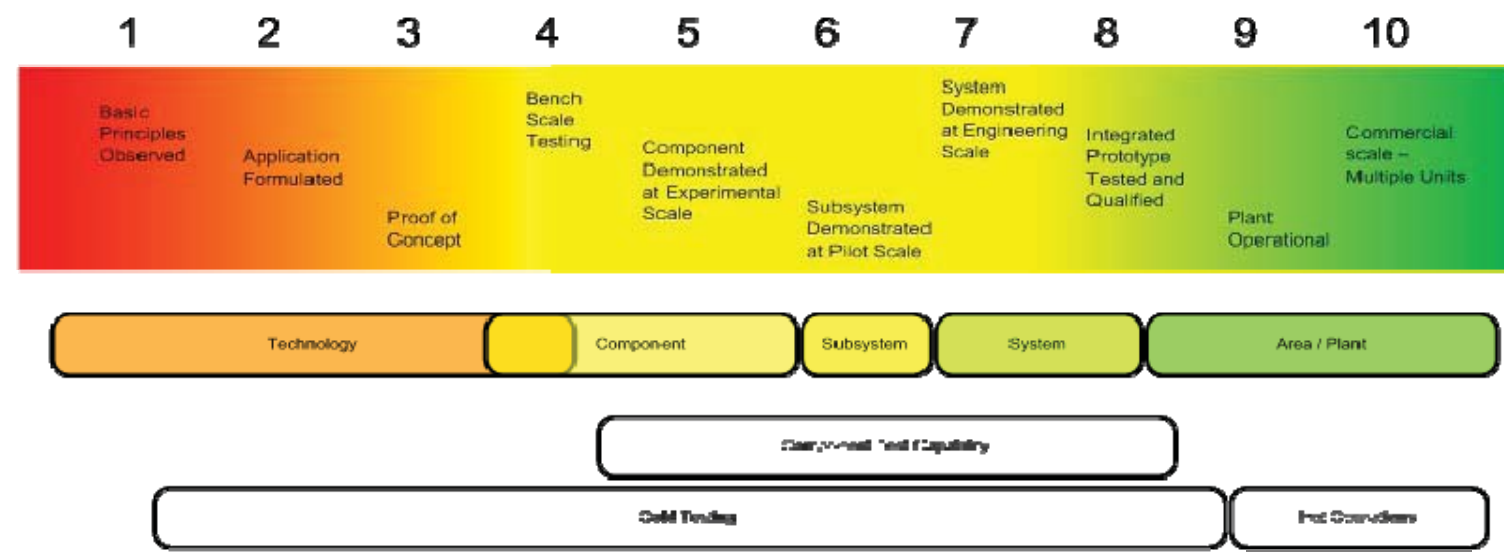

Figure 2. Technology Readiness Levels

These TRL ratings:

- Establish the current state of proposed technologies that are used as the starting point for TRLs

- Provide a consistent measure of readiness levels and confidence in the levels as inputs to quantifying performance, cost, and schedule risks.

The TRLs serve as an excellent measure to ensure that engineering design and R\&D interface in the maturation of the needed technology. For TRLs 1-5, assessment typically occurs on an individual technology or component with a calculated roll up TRL for the associated area, 
systems, and subsystems. As the technology or component progress to further levels of maturity, integrated testing occurs to allow TRL assessments directly against subsystems and systems. The integrated testing or modeling occurs at increasingly larger scales and in increasingly relevant environments, thus achieving higher TRL ratings.

The Idaho National Laboratory (INL) worked closely with subject matter experts from the public and private sectors to identify the critical components that make up the NGNP. The assessment included a review of the potential architecture and concept of operations required for an NGNP that satisfies the stakeholder requirements. It was determined that the NGNP, which is divided into five areas, has 16 critical SSCs. These components were analyzed to determine their technical readiness.

Critical SSCs are defined as those items that are not commercially available or have not been

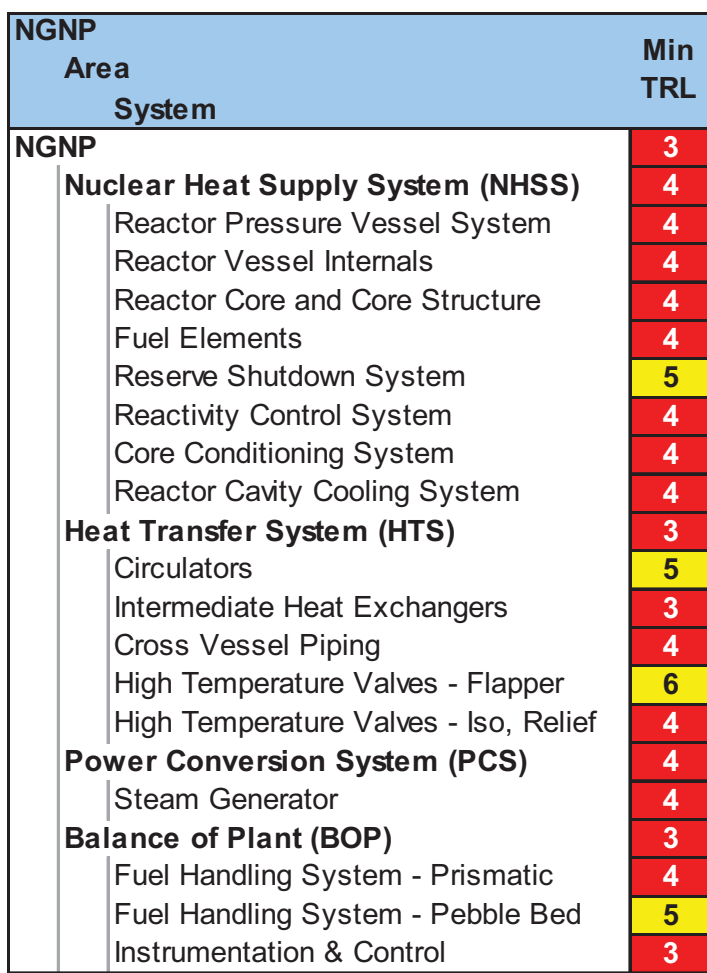

Figure 3. Identified Critical SSCs proven in relevant industry environments, at appropriate scale, or fully integrated with other components. As such, the critical SSCs for the NGNP, as shown in Figure 3, typically have a TRL rating of less than 7 . Components that had not been demonstrated at the temperature and pressure anticipated in NGNP's helium environment could not be rated at high TRLs. Similarly, components with significant materials issues attained TRL ratings of 3 or 4 .

Just as immature technologies inserted into a plant can cause problems, designs need to advance to the point of informing R\&D of the tasks needed to better the design. As depicted in Figure 4, very high risks are acceptable to the project during pre-conceptual design and at early levels of technology readiness. However, as the project advances through final design, risks must be driven to moderate and low, and technology readiness advanced to higher levels. 


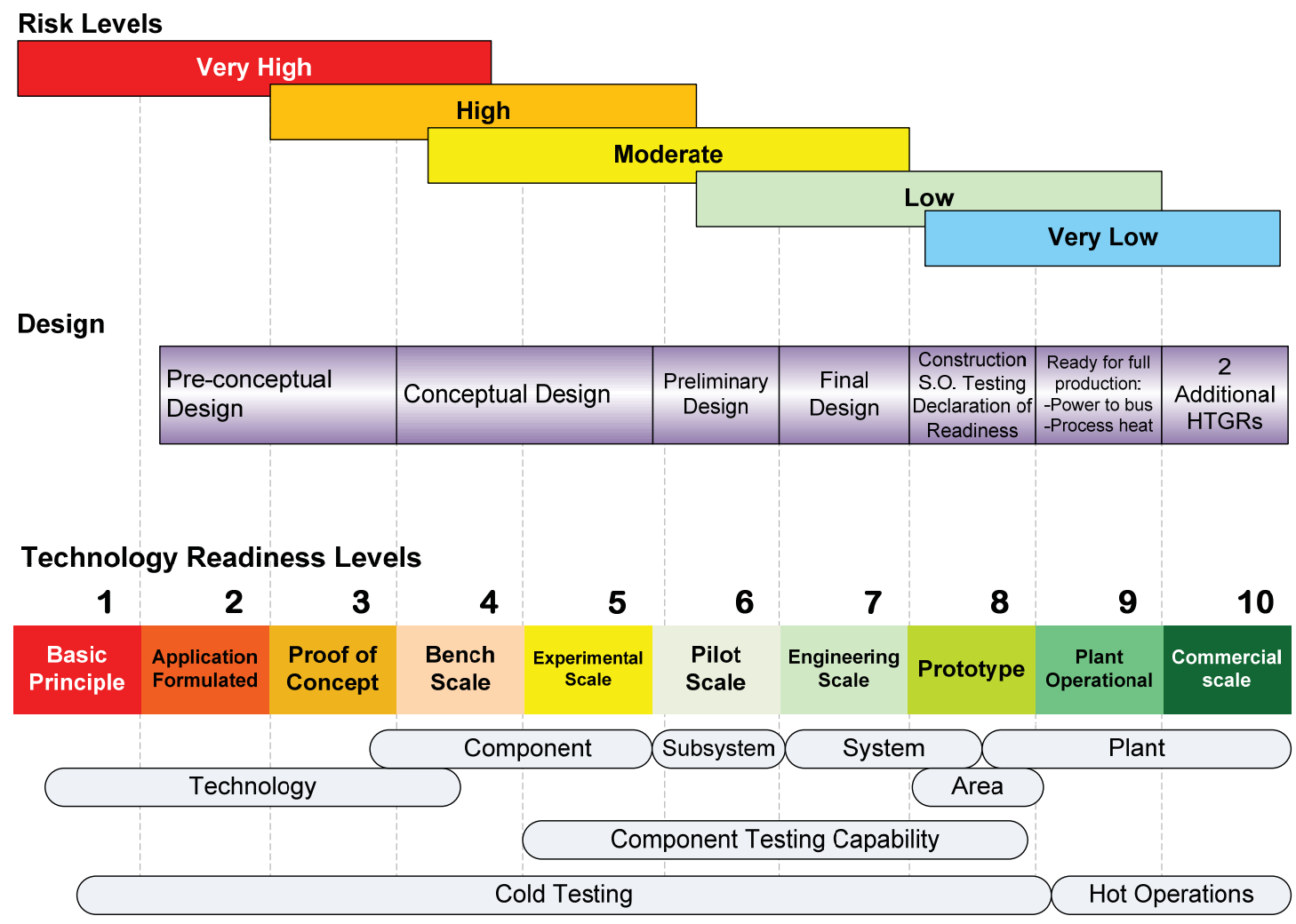

Figure 4. Design, Risk, and Technology Readiness Advance in Parallel

\section{Technology Development Roadmaps}

With the baseline SSCs and their associated TRLs defined, a TDRM is developed to guide the needed maturation. The TDRM process identifies the key selection discriminators; defines tasks for down selection of technologies; documents current TRL baselines; defines tasks to mature technologies; and establishes test plans to achieve selected TRL step change milestones. The steps in the process include Structure Identification, Technology Readiness Assessment, Technology Selection, Technology Maturation, and Test Plan Development. The resulting roadmaps set the project course for technology selection, qualification, and maturation in a fashion that enhances project performance and facilitates on-schedule and on-budget success.

An early step in technology maturation is to select between competing technologies. In technology down selection, decision discriminators are developed as the important parameters that a successful technology would have to satisfy to assist NGNP in meeting its mission. This list of parameters is then consolidated into key selection discriminators that focus the data collection on the parameters important to the NGNP, namely those that distinguish the benefits of one technology from another. Typically, technologies or components must be matured to a TRL of 5 to proceed with down selection when the technologies are sufficiently understood and the risks of making the wrong choices are minimized. Where appropriate, the units of the discriminator are determined. This ensures that the discriminator is indeed measureable. Typical technology down selection tasks are as follows: 
- Identify all decision discriminators

- Consolidate decision discriminators

- Define decision discriminators (units and equations)

- Determine level of data needed (qualitative, semi-quantitative, quantitative)

- Determine the tasks required to obtain the discriminating information necessary to perform the comparison of alternatives and ultimate down selection. These tasks will include studies, tests, evaluations, modeling, simulations, qualitative analysis, and quantitative analysis.

The down selection and needed data gathering activities are depicted in the TDRM. Down selection often results in a preferred technology along with backup technologies. The TDRM is used to depict the performance criteria that the primary technology must achieve as well as "off ramps" to the backup technology in the event that the primary technology fails to meet the required performance criteria.

The TDRMs visually depict the current TRL of critical SSCs; the steps required to advance the system to the desired end state; the schedule associated with TRL advancement activities; related design decisions, alternatives, and discriminators; and a summary of the major risks. Ultimately, the TDRM process helps to focus R\&D efforts and engineering studies on the known risks to advancing the selected technology and satisfying the increasingly demanding and scaled up tests. As the technology achieves the performance criteria required for advancing technology readiness, the uncertainty associated with the successful implementation of that technology is reduced. The probability of realizing negative consequences is also reduced as technologies are demonstrated in increasingly relevant environments, at larger scales, and in integrated settings (i.e., increased technology readiness levels), as shown in Figure 5.

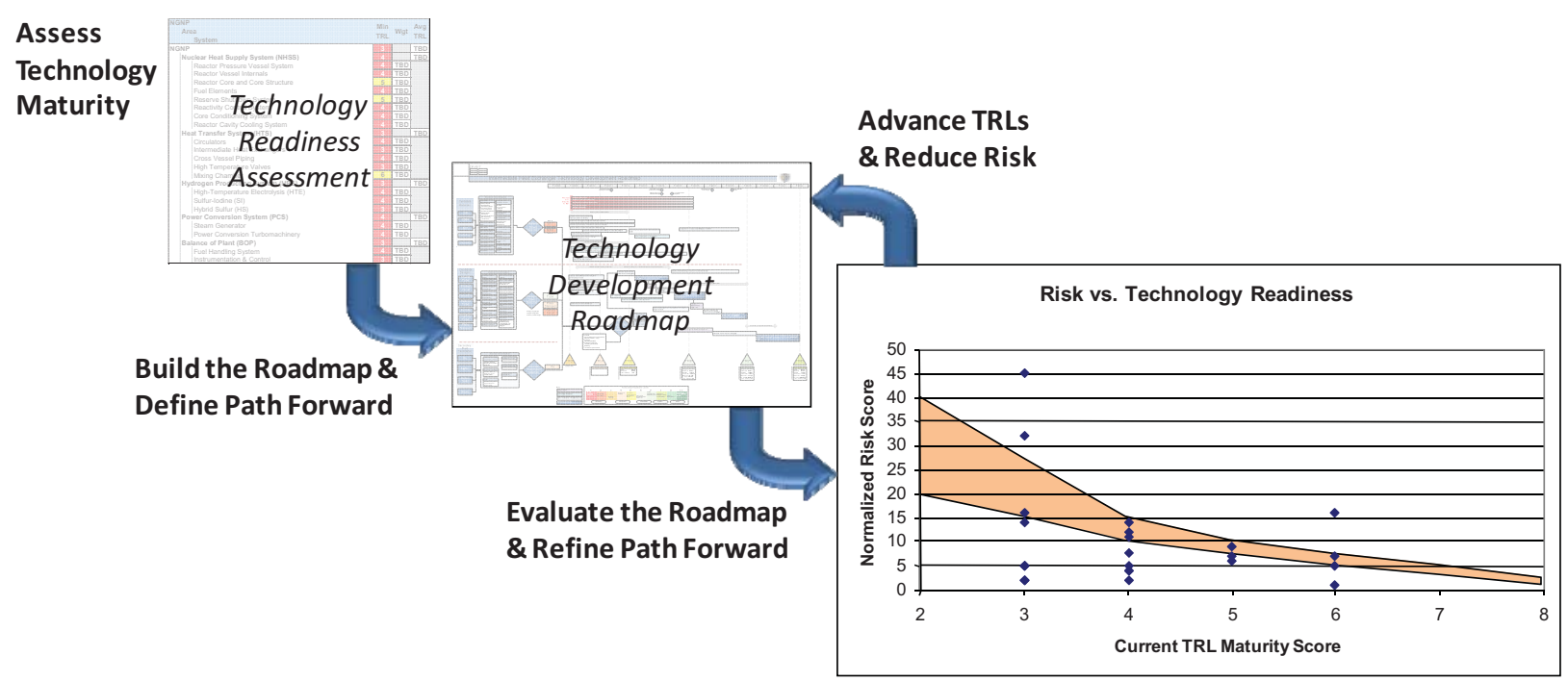

Figure 5. Executing the Roadmap increases Readiness while Reducing Risk.

In the NGNP application, TDRMs provide the required structure and are the primary means to systematically perform risk-informed decision making, risk reduction, technology down 
selection, and technology qualification and maturation in a cost-effective and timely manner. Additionally, TDRMs serve to coordinate engineering, R\&D, and licensing efforts efforts and to mitigate risks early in the NGNP project. Technology roadmaps for the 16 critical NGNP SSCs were developed to:

- Set the vision for maturing technologies to the required TRL

- Identify the key selection discriminators and drive the needed actions to down select technologies and designs

- Ensure technology readiness is demonstrated through testing, modeling, simulations, piloting, and prototyping, as appropriate

- Provide early identification and resolution of technical risks

- Avoid late project technical challenges, which manifest themselves as cost overruns and schedule delays

- Develop the test plans to provide demonstrable evidence of the technology maturation required for codification and qualification.

The set of TDRMs along with their associated documentation represent the path forward for the NGNP project to complete its mission, which consists of the research, development, design, construction, and operation of a prototype nuclear plant. Performance criteria are shown on the TDRM as a basis for TRL advancement.

The major technical risks identified for each critical SSC represent the overall uncertainties that must be addressed and reduced to enhance the probability of a successful NGNP. These risks are generally reduced as a technology is developed per the tasks in the TDRMs. A risk that is not shown but requires addressing each of the SSCs is one of system interconnectivity. Interconnectivity is proven and further reduced as one tests integrated and large-scale systems rather than mere components. This risk is not reduced sufficiently until the NGNP is system operability tested and successfully receives a TRL of 8 . The majority of risk should be reduced prior to achieving a TRL of 5. To reduce cost and schedule overruns, the TDRMs are designed to reduce risk at the lowest possible TRL.

\section{Integrated Schedule and Prioritization}

Once the TDRM is developed with the tasks necessary for TRL advancement and risk reduction, these tasks can be used as a framework or input to the overall integrated schedule for the project. The tasks are laid out on the TDRM in time order, which enables an easy transfer to an integrated schedule. Detailed TDRM tasks can then populate the integrated schedule for planning and execution.

\section{Conclusion}

Roadmaps are used to identify and assess the current state of technology; create a consensus vision of R\&D and engineering studies required to advance technology; focus R\&D resources; provide a structured, defensible decision project plan; expedite new systems deployment; and minimize project costs and schedules. Adapting INL's proven technology roadmapping methodology and tools to the project remediation challenge can realize the following benefits: 
- Measure the merit of relevant technologies

- Accelerate application of new technologies

- Facilitate informed decision-making

- Reduce risks associated with system and technology integration.

\section{References}

American Forest \& Paper Association, Agenda 2020 Technology Alliance. 2003. Agenda 2020 Forest Products Industry Technology Alliance 2003 Progress Report. Washington, D.C.: American Forest \& Paper Association.

Collins, John W. 2002. Roadmapping - a tool for strategic planning and leveraging R\&D completed by other agencies. Waste Management Conference, Tucson, AZ, 24-28 February.

Glass: A Clear Vision for a Bright Future. 1996. Developed by representatives of the glass industry, with advice from research institutions and other organizations.

Government Accountability Office. 2002. Department of Energy: Major Construction Projects Need a Consistent Approach for Assessing Technology Readiness to Help Avoid Cost Increases and Delays. GAO-07-336. Report to the Subcommittee on Energy and Water Development, and Related Agencies, Committee on Appropriations, House of Representatives.

Grinnell, Mary, Jim Richey, and Erica McQueen. 2002. Case Study: Innovative Roadmapping Using Enterprise Automation Software. Motorola.

Thompson, D., J. R. Hess, R. Hoskinson, and T. D. Foust. 2003. Roadmap for Agricultural Biomass Feedstock Supply in the United States. DOE-NE-ID-11129. Washington, DC: U.S. Department of Energy.

U.S. Department of Defense. 2009. Technology Readiness Assessment (TRA) Deskbook. Prepared by the Research Directorate, Office of the Director, Defense Research and Engineering.

U.S. Department of Energy. 2000. Applying Science and Technology Roadmapping in Environmental Management. Draft B. Washington, D.C.: U.S. DOE Office of Environmental Management.

-. 2002. A Technology Roadmap for Generation IV Nuclear Energy Systems. 03GA50034. Prepared by the U.S. DOE Nuclear Energy Research Advisory Committee and the GEN IV International Forum.

\section{Biography}

John W. Collins, CSEP and Chief Systems Engineer at the Idaho National Laboratory for the Next Generation Nuclear Plant, started his career as a Technical Shift and Start up Engineer. John led projects to retrofit analog instruments and controls to digital with computer automation and managed the defueling of reactors domestically and internationally. John, a Project Management Professional and Certified Systems Engineering Professional, has 26 years in project and program management, risk and requirements management, decision making, and strategic planning. A Chemical Engineer by education, John managed Electrical and 
Instrument/Controls, Engineering, Spent Nuclear Fuel, and Nuclear Material Consolidation Projects.

Layne Pincock is a Systems Engineer at the Idaho National Laboratory for the Next Generation Nuclear Plant. Layne has participated in a wide variety of systems engineering projects during his career at the Idaho National Laboratory, including a large integration project across many Department of Energy Sites. Layne also worked on the license application for the Yucca Mountain Project. Layne is a mechanical engineer by education.

\section{Disclaimer}

This manuscript has been authored by Battelle Energy Alliance, LLC under Contract No. DEAC07-05ID14517 with the U.S. Department of Energy. The United States Government retains and the publisher, by accepting the article for publication, acknowledges that the United States Government retains a nonexclusive, paid-up, irrevocable, world-wide license to publish or reproduce the published form of this manuscript, or allow others to do so, for United States Government purposes.

\section{Contact Information}

John W. Collins, 2525 Fremont St, Idaho Falls, Idaho 83415; Tel: 208-526-3372; Fax : 208-5264313; Email : john.collins@inl.gov 